\title{
A precipitation-based regionalization for Western Iran and regional drought variability
}

\author{
T. Raziei $^{1}$, I. Bordi ${ }^{2}$, and L. S. Pereira ${ }^{3}$ \\ ${ }^{1}$ Soil Conservation and Watershed Management Research Institute (SCWMRI), Tehran, Iran \\ ${ }^{2}$ Department of Physics, University of Rome "La Sapienza", Rome, Italy \\ ${ }^{3}$ Agricultural Engineering Research Center, Institute of Agronomy, Technical University of Lisbon, Lisbon, Portugal
}

Received: 30 June 2008 - Published in Hydrol. Earth Syst. Sci. Discuss.: 5 August 2008

Revised: 13 October 2008 - Accepted: 27 October 2008 - Published: 10 December 2008

\begin{abstract}
The spatial distribution of the seasonal and annual precipitation was analyzed in western Iran using data from 140 stations covering the period 1965-2000. Applying the Precipitation Concentration Index (PCI), the intraannual precipitation variability was also studied. Furthermore, nine precipitation-derived parameters were used to regionalize climate in western Iran using principal component analysis and clustering techniques. Results suggest that five spatially homogenous sub-regions can be identified characterized by different precipitation regimes. The spatial pattern of seasonal precipitation seems to be highly controlled by the wide latitudinal extent of the region and by the pronounced orographic relieves, and the time of occurrence of the maximum precipitation varies from spring in the north to winter in the south.

The time variability of dry and wet periods in the identified sub-regions was analyzed using the Precipitation Index (PI) and the existence of any long-term trend was tested. Results show that the northern and southern regions of western Iran are characterized by different climatic variability. Furthermore, a negative long-term linear trend in the north and a weak positive trend in the south of the study area have been detected though they are not statistically significant.
\end{abstract}

\section{Introduction}

Iran with approximately $1600000 \mathrm{~km}^{2}$ is one of the vast countries. Climate in Iran is mainly controlled by the wide latitudinal extent (from $25^{\circ} \mathrm{N}$ to $40^{\circ} \mathrm{N}$ ) and by the pro- nounced relieves, that is the Zagros and Alborz mountain systems. The moisture coming from the Persian Gulf is usually stopped by the Zagros Mountains. The plateau is open to the cold (dry) continental currents flowing from the northeast and the mitigating influence of the Caspian Sea is limited to the northern regions of Alborz Mountains (Fig. 1a). Furthermore, the Zagros chain, which stretches from northwest to southeast, is the source of several large rivers such as Karkheh, Dez, and Karoon. Lowland areas receive surface water from these basins and are of great importance for agricultural production, namely through irrigation; water is also diverted from western Zagros slopes to the eastern part of the country, including for irrigated agriculture.

The precipitation amount highly varies over the country. There are regions in the south of the Caspian Sea or in the Zagros Mountains that receive up to $2000 \mathrm{~mm}$ of annual precipitation, whereas a portion of southern and eastern part of Iran gets less than $50 \mathrm{~mm}$. Furthermore, most of the precipitation in Iran falls during the winter and autumn seasons due to the prevalence of humid westerly winds of Mediterranean origin (Domroes et al., 1998; Dinpashoh et al., 2004). Differently, there are regions in the northwestern part of the country that have the largest share of precipitation during spring. Owing to this high spatial and temporal variability of precipitation and frequent dry periods, the increasing water demands for an ever growing population as well as for industry and economic development, including irrigation, aggravate water scarcity and make difficult a rationale water management. Hence, the definition of sub-regions characterized by different precipitation regimes is of great importance for water resources management and land use planning. 


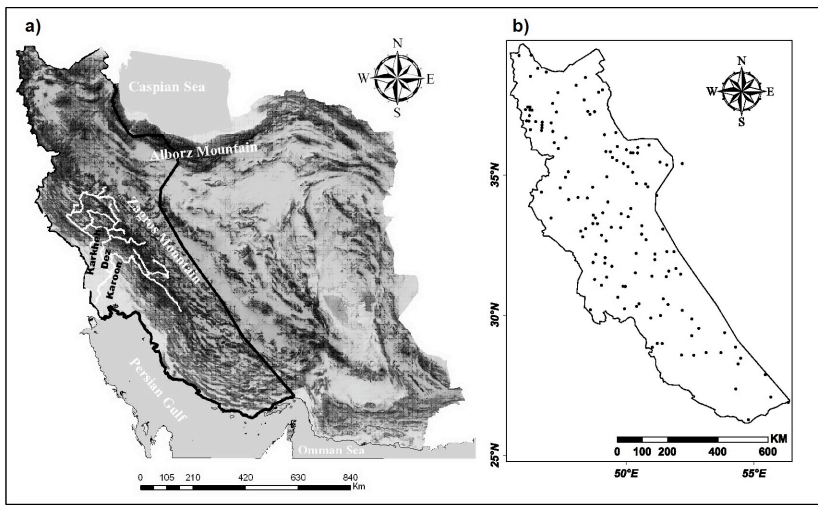

Fig. 1. (a) Topographic map of Iran and (b) stations network across the study area.

Due to the shortness of climatological data length and the sparse distribution of the Iranian meteorological stations across the country, just a few precipitation regionalization studies have been performed (Domroes et al., 1998; Dinpashoh et al., 2004; Soltani et al., 2007). Domroes et al. (1998) used a network of 71 stations distributed irregularly across Iran. They applied the Principal Component Analysis (PCA) and Cluster Analysis (CA) on mean monthly precipitation of those 71 sites and classified the precipitation regimes into five different sub-regions. On the other hand, applying the PCA and CA to 12 variables selected from 57 candidate variables for 77 stations distributed across the entire country, Dinpashoh et al. (2004) divided the country into seven climate sub-regions. Rainfall climates in Iran were also analyzed by Soltani et al. (2007) using monthly precipitation time series from 28 main sites. To determine regional climates a hierarchical cluster analysis was applied to the autocorrelation coefficients at different lags, and three main climatic groups were found. In these studies, since spatially not homogeneously distributed stations were considered and different methodologies were applied, the identified sub-regions differ from one study to another, especially in mountainous regions of western Iran, that are characterized by a complex orography. Therefore, further research is necessary for western Iran to delineate adequate climate subregions that properly represent the real variability of precipitation regimes in the area. Motivated by this issue and since western Iran enjoys a dense precipitation measurement network of good quality with data from 1965 to 2000, a new precipitation-based regionalization is proposed herein. Furthermore, the time variability of dry/wet events in the identified sub-regions is investigated by analyzing the standardized annual precipitation anomaly.

The present study also responds to the need to complement an analysis on drought variability in western Iran (Raziei et al., 2008). In that study, the temporal and spatial variability of hydrological drought in western Iran has been analyzed by applying the Principal Component Analysis (PCA) to the Standardized Precipitation Index (SPI) computed on 12-month time scale. In particular, two sub-regions characterized by different climatic variability have been identified in relation to dry/wet events, and long-term trends in the SPI time series have been analyzed. Herein, we provide the new climate regionalization based on precipitation using the same station network in western Iran. In fact, these two kinds of analyses (drought variability and precipitation variability), though conceptually different, complement each other and can contribute to a better management of water resources in the area.

The paper is organized as follows: in Sect. 2 the study area and the data used for the analysis are presented, while in Sect. 3 there is a description of methodology. Section 4 illustrates the main results and Sect. 5 provides the conclusions and an outlook for future investigations.

\section{The study area and data}

This study focus on western Iran, that extends between the latitudes $26^{\circ} \mathrm{N}$ and $39^{\circ} \mathrm{N}$ and the longitudes $45^{\circ} \mathrm{E}$ and $51^{\circ} \mathrm{E}$ (Fig. 1a), covering an area of about $607143 \mathrm{~km}^{2}$. It is located on a transitional region of the westerlies main track and average location of the Sub-Tropical High Pressure (STHP) (Alijani, 1997). The area is largely occupied by the Zagros Mountain system (Fig. 1a), which is located across the paths of the prevailing moisture bearing and westerlies, with precipitation of 200 to $600 \mathrm{~mm} \mathrm{year}^{-1}$ (Domroes et al., 1998; Dinpashoh et al., 2004). Due to the latitudinal extent and the complex relief structures, the precipitation amount highly varies over the region. Hence, a few sub-regions characterized by different precipitation regimes are expected across the western Iran.

Monthly precipitation data for 196 stations in the region were made available by the Iranian Water Resources Institute and the Iranian Meteorological Organization. The randomness of the annual data sets was investigated through tests for homogeneity, absence of artificial trends and spurious autocorrelation. Following Helsel and Hirsch (1992), a set of non-parametric tests was applied: the Mann-Whitney homogeneity test, the Mann-Kendall trend test and the Kendall's $\tau$ autocorrelation test. These tests were performed for all stations as described by Paulo et al. (2003) using software developed by Matias (1998). The test results led to discard 56 stations having low quality data and/or more than 5\% missing values. The remaining 140 stations cover 35 hydrological years, from October 1965 to September 2000, and constitute a well-distributed network throughout the study area (Fig. 1b). Missing values for each station were estimated using the Move4 technique (Maintenance of Variance Extension), which develops a linear equation such that a reasonable and unique extended record is generated maintaining unchanged the variance of the data series (Vogel and Stedinger, 1985). 


\section{Methods}

Traditional classifications of climates are those developed by Köppen (1923) and Thornthwaite (1931). The modern climate regionalization often utilizes Principal Component Analysis (PCA) and/or Cluster Analysis (CA) techniques to define climate zones based on single or multi-climate variables (e.g., Kalkestein et al., 1987; Ehrendorfer, 1987; White et al., 1991; Dinpashoh et al., 2004, and references therein). This approach is adopted in the present study using precipitation as the basic parameter, hence making the analysis compatible with that performed on drought using the Standardized Precipitation Index (Raziei et al., 2008).

To study the leading modes of precipitation variability in western Iran the following variables have been considered as input for PCA: the time mean of the cumulated seasonal precipitation, the percentage of annual precipitation amount occurring in each season of the year, and the Precipitation Concentration Index (PCI).

For the computation of seasonal (cumulated) precipitation, four seasons are defined following the hydrological year: autumn (October, November, December), winter (January, February, March), spring (April, May, June) and summer (July, August, September).

The PCI, which is an intra-annual precipitation variability index (De Luís et al., 2000, 2001), is defined as:

$$
\mathrm{PCI}=100 \frac{\sum_{i=1}^{12} P_{i}^{2}}{\left(\sum_{i=1}^{12} P_{i}\right)^{2}},
$$

where $P_{i}$ is the mean rainfall of the $i$-th month at each station. The index ranges from less than 10 to 100 . PCI values below 10 indicate a uniform monthly rainfall distribution over the year, whereas values from 11 to 20 denote seasonality in rainfall distribution. Values above 20 correspond to climates with substantial monthly variability in rainfall amounts (De Luís et al., 2000). Thus, maps of PCI values provide a good visual guide to the spatial variability of monthly precipitation across a given study area.

\subsection{Principal component analysis}

Principal Component Analysis is a useful method that has been widely applied in climatology and meteorology for data reduction purposes. This method reduces inter-correlated variables to some linearly uncorrelated ones called principal components (PCs), which account for as much as possible of the variation in the original variables. The method is based on the computation of the eigenvalues and eigenvectors of either the correlation matrix or the covariance matrix of the observed variables. Depending on the aims of the study and kinds of variables considered, data can be arranged in different types of matrices as input for PCA, which are called
Table 1. Varimax rotated PC loadings, eigenvalues, explained variances and cumulative variances. In the first column there are the nine variables used for the PCA. Loading values greater than 0.7 or less than -0.7 are in bold.

\begin{tabular}{|c|c|c|c|c|}
\hline Variables & $\mathrm{PC}_{1}$ & $\mathrm{PC}_{2}$ & $\mathrm{PC}_{3}$ & $\mathrm{PC}_{4}$ \\
\hline $\begin{array}{l}\text { Mean autumn } \\
\text { precipitation amount }\end{array}$ & 0.18 & 0.92 & -0.18 & 0.27 \\
\hline $\begin{array}{l}\text { Mean winter } \\
\text { precipitation amount }\end{array}$ & -0.26 & 0.94 & -0.23 & 0.01 \\
\hline $\begin{array}{l}\text { Mean spring } \\
\text { precipitation amount } \\
\text { Mean summer }\end{array}$ & 0.89 & 0.39 & 0.13 & -0.15 \\
\hline $\begin{array}{l}\text { precipitation amount } \\
\text { Percentage of }\end{array}$ & 0.39 & -0.15 & 0.85 & -0.28 \\
\hline $\begin{array}{l}\text { Percentage of } \\
\text { autumn precipitation } \\
\text { Percentage of }\end{array}$ & -0.08 & 0.19 & -0.37 & 0.90 \\
\hline $\begin{array}{l}\text { winter precipitation } \\
\text { Percentage of }\end{array}$ & -0.90 & 0.29 & -0.27 & -0.11 \\
\hline $\begin{array}{l}\text { Percentage of } \\
\text { spring precipitation } \\
\text { Percentage of }\end{array}$ & 0.92 & -0.26 & 0.22 & -0.18 \\
\hline summer precipitation & 0.28 & -0.40 & 0.80 & -0.29 \\
\hline PCI & -0.93 & -0.03 & -0.24 & 0.03 \\
\hline Eigenvalue & 3.66 & 2.25 & 1.77 & 1.13 \\
\hline $\begin{array}{l}\text { Percentage of } \\
\text { explained variance } \\
\text { Cumulative percentage }\end{array}$ & 40.63 & 25.02 & 19.71 & 12.51 \\
\hline $\begin{array}{l}\text { Cumulative percentage } \\
\text { of explained variance }\end{array}$ & 40.63 & 65.65 & 85.36 & 97.87 \\
\hline
\end{tabular}

modes of PCA (Richman, 1986). For example, in studying precipitation variability, the S-mode PCA identifies the covariability of precipitation time series at given stations across the study area (data matrix where rows correspond to the observations and columns refer to the stations). Differently, the R-mode PCA reveals the interrelationship among the variables/parameters considered (data matrix with rows for the stations and columns for the climate variables). In this study, the nine variables listed in the first column of Table 1 are used as input for the R-mode PCA. As the selected parameters are measured in different units, they were standardized prior to further analysis. By this method the nine variables can be classified into groups in such a way that in each group they have similar distributions in space, i.e. high spatial covariability (Lolis et al., 1999).

An orthogonal rotation based on Varimax criterion is widely used to obtain more spatially localized and uncorrelated PCs (Von Storch and Zwiers, 1999). The decision regarding how many PCs to retain for rotation can be based on scree plot of the eigenvalues and the North rule of thumb (North et al., 1982). In this study, following this rule, which is based on the estimation of the sampling errors of the eigenvalues associated to the principal components, the first four PC scores have been retained for Varimax rotation. 


\subsection{Cluster analysis}

For the spatial classification of precipitation over western Iran an agglomerative hierarchical cluster analysis was applied to the rotated PC scores using the Ward algorithm. Cluster Analysis attempts to detect those observations or objects that are most similar and categorize them together into one or more clusters. All clustering methods, including hierarchical, non-hierarchical and K-means, are designed to maximize within-group similarity and to minimize betweengroup similarity (Bunkers et al., 1996). To achieve this purpose, some measures of similarity or distance between pairs of observations/objects must be created. The most commonly used distance measure is the Euclidean distance (Fovell and Fovell, 1993).

In the present study, to determine the groups of stations with similar characteristics, the decision was based on the inspection of the plot of the distances between merged clusters as a function of the stage of the analysis (Wilks, 1995; Muñoz-Diaz and Rodrigo, 2004).

\subsection{Standardized precipitation anomaly}

In monitoring the duration and intensity of drought over a region, Kraus (1977) proposed the Standardized Anomaly Index, also called Precipitation Index (PI) (Delitala et al., 2000). This index involves standardizing the annual (seasonal or monthly) total rainfall for an individual station and then averaging these standardized anomalies over all the stations within the region to obtain a single value (Katz and Glantz, 1986; Delitala et al., 2000), i.e. at time $t$ we have:

$\hat{\mathrm{PI}}_{t}=\frac{1}{N_{t}} \sum_{j=1}^{N_{t}} \frac{\left(P_{j t}-\mu_{j}\right)}{\sigma_{j}}$,

where $P_{j t}$ is the precipitation ( $\mathrm{mm}$ ) at the station $j$ at time $t$ (usually a year, a season or a month), $\mu_{j}$ and $\sigma_{j}$ are the mean and standard deviation for the precipitation at the same station $j$, and $N_{t}$ is the number of stations available at time $t$.

However, in order to make comparisons of the index values among different regions, it is desirable that the index has fixed expected value and variance. Since $\hat{\mathrm{PI}}_{t}$ involves deviations from the single station means, its expected value is necessarily zero, while, in general, the variance of the index depends upon the spatial correlations among the precipitation at the $N_{t}$ sites and on the number of stations used (Katz and Glantz, 1986; Delitala et al., 2000). To solve this problem a re-weight of the index is usually done as:

$\mathrm{PI}_{t}=\frac{1}{S_{t} N_{t}} \sum_{j=1}^{N_{t}} \frac{\left(P_{j t}-\mu_{j}\right)}{\sigma_{j}}$,

where $S_{t}$ is the standard deviation of $\mathrm{PI}_{t}$ (see Kats and Glantz, 1986).
In the present study we used the annual precipitation as basic variable for the computation of the $\mathrm{PI}_{t}$. Furthermore, as proposed by Kraus (1977), a variance analysis has been applied to the $\mathrm{PI}_{t}$ time series prior to further analysis to assess whether these time series are representative for the subregion as a whole, i.e. if the geographical variations of the index between different places within the sub-region are small compared to the temporal year-to-year fluctuations. The statistical importance of the ratio of variance estimates (variance in time/variance in area) has been determined by a $\mathrm{F}$ test. The regional annual $\mathrm{PI}_{t}$ time series were also checked for normality, which is a prerequisite for the analysis, using the K-S and Anderson-Darling goodness of fit tests. Test results showed that the $\mathrm{PI}_{t}$ time series follow a normal distribution with $95 \%$ confidence level.

To unveil the presence of any long-term trend, the linear least square model was fitted to the regional annual $\mathrm{PI}_{t}$ time series and the related Mann-Kendall statistics has been applied.

\section{Results}

\subsection{Spatial variability of annual and seasonal precipitation}

The spatial pattern of annual cumulated precipitation in western Iran is shown in Fig. 2. It can be seen that the lowest annual precipitation, less than $300 \mathrm{~mm}$, occurs in the east, south, southwest and northern foothills areas of Zagros mountain chain. Following the orography, the annual precipitation amount increases from all orientations toward the highlands. In the ridge of the Zagros Mountain, it reaches its maximum, with the annual precipitation close to $1500 \mathrm{~mm}$. Such high annual precipitation core is not noticeable in the previous studies by Domroes et al. (1998) and Dinpashoh et al. (2004), since they used only synoptic and climatological stations, which are mostly located in cities and low elevation sites.

Figure 3 presents the spatial patterns of cumulated precipitation amounts for the four seasons. Figure $3 \mathrm{a}$ and $\mathrm{b}$ shows that the highest precipitation amounts in autumn and winter in the study area occur in western Zagros, with 400 and $800 \mathrm{~mm}$, respectively. From the Zagros' ridge outward, the amount of precipitation diminishes in all directions following the decrease in elevation. The lowlands and foothills of Zagros, in the south, north and east, have much lower precipitation than the mountains in both seasons; some areas receive less than 50 and $100 \mathrm{~mm}$ respectively in autumn and winter.

Figure $3 \mathrm{c}$ and $\mathrm{d}$ shows that the cumulated precipitation in spring and summer is higher in the northern sector than in the other parts of the region. The maximum spring precipitation occurs in mid-west, with more than $200 \mathrm{~mm}$, and in northern areas, with $100 \mathrm{~mm}$. In contrast, lowest 


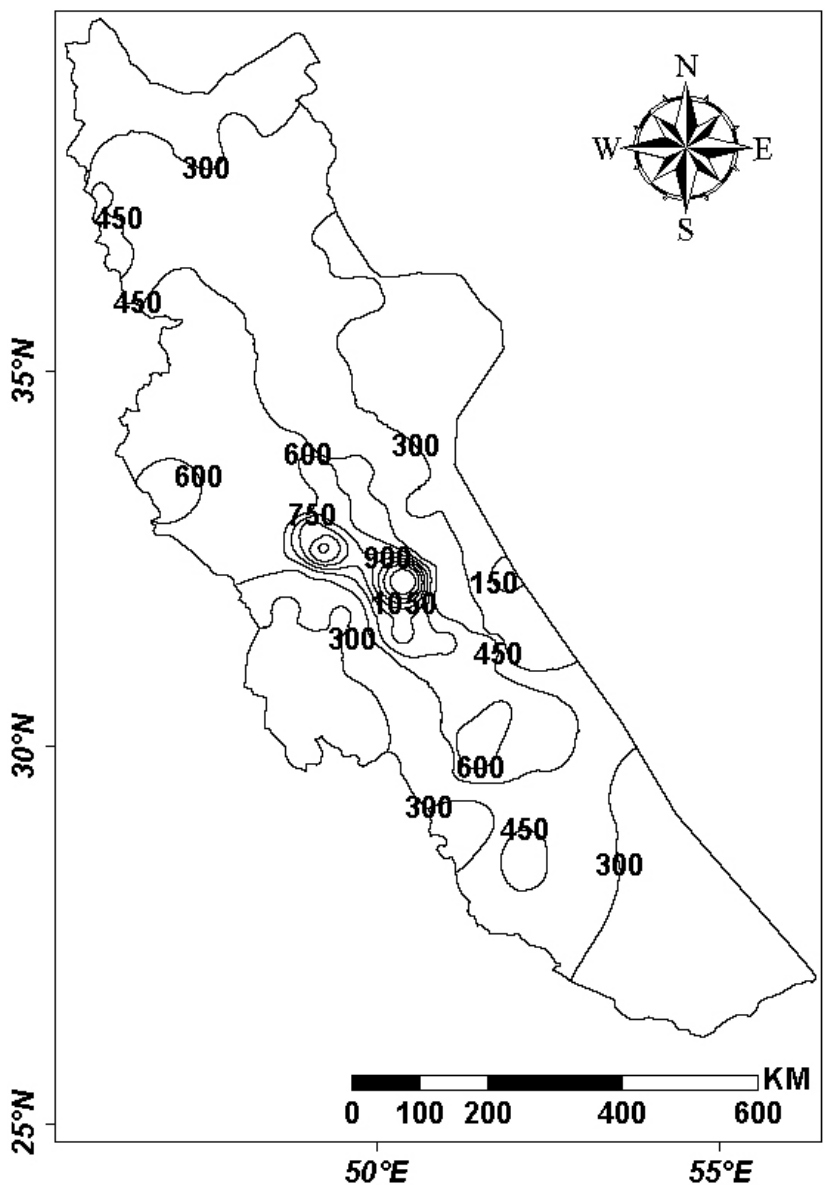

Fig. 2. Spatial distribution of the mean annual precipitation in western Iran. Unit is mm.

precipitation in spring occurs in southern areas. The highest summer precipitation occurs in the north, while most of the region is without precipitation during this season.

To assess the temporal distribution of precipitation within the year, the percentage of seasonal precipitation contributing to the annual precipitation amount across the western Iran is presented in Fig. 4. Figure 4a and $\mathrm{b}$ shows the share of autumn and winter precipitation, respectively. Most of the region receives about 20 to $30 \%$ of annual precipitation in autumn, and only a small part, in the southwest, has a higher share, representing 35 to $40 \%$ of the annual precipitation. Figure $4 \mathrm{~b}$ shows that, except for the northern part, the winter is the main rainy season in the region, particularly in the south. The contribution of winter precipitation to the total annual precipitation increases from less than $40 \%$ in the north to $70 \%$ in the south. In spring, the south and southwest areas receive less than $10 \%$ of annual precipitation (Fig. 4c). Differently, the spring precipitation in the north reaches the largest share, more than $30 \%$ of the total annual precipitation. Most of the study area receives no rainfall in summer (Fig. 4d). However, some locations may occasionally get
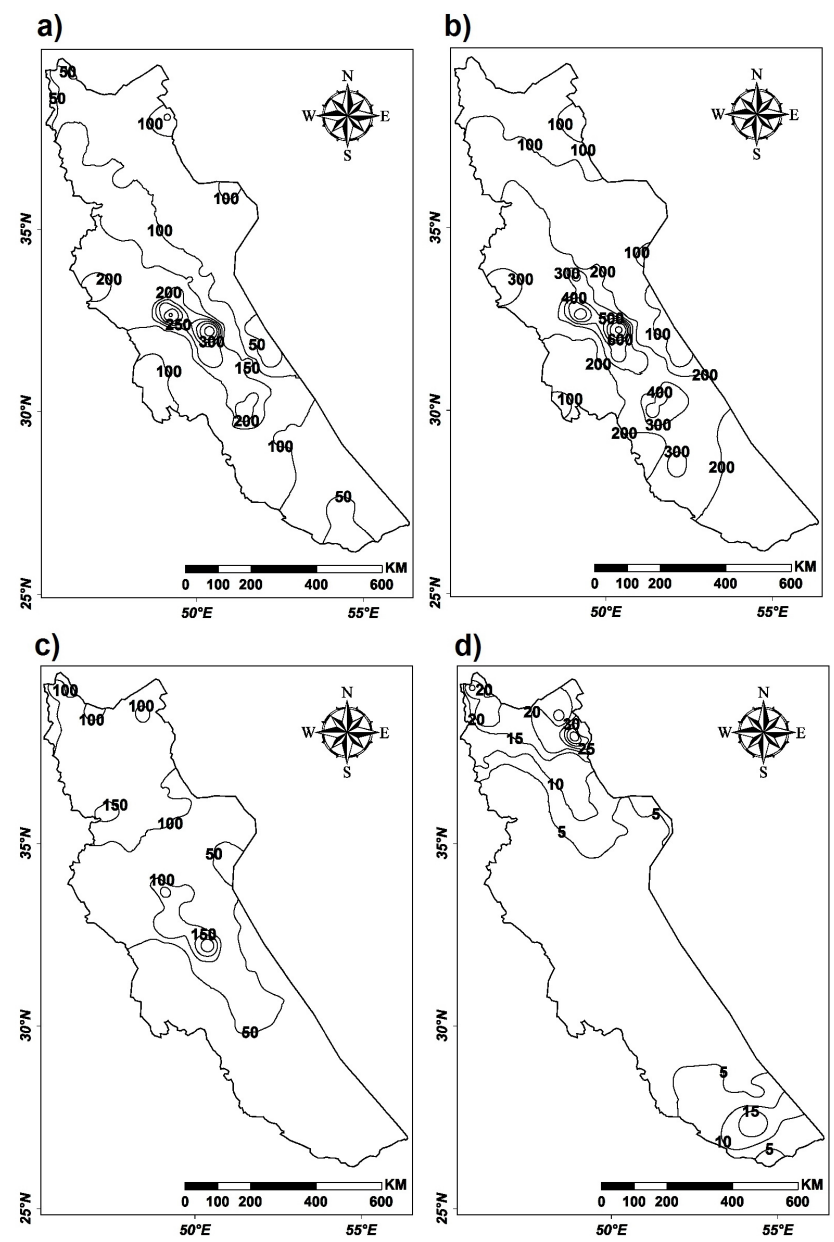

Fig. 3. Mean seasonal precipitation amounts: (a) autumn, (b) winter, (c) spring and (d) summer in western Iran. Unit is $\mathrm{mm}$.

summer rainfall due to convective activity, but the maximum share of summer precipitation in the region is smaller than $10 \%$. Therefore, the spatial pattern of this season is almost uniform across the study area.

Figures 2 to 4 suggest that the spatial variability of precipitation in the western Iran is largely influenced by orography and latitude. In particular, spatial patterns of annual, winter and autumnal precipitation amounts are largely controlled by orographic relieves, while the latitude mainly influences spring and summer precipitation. Moreover, these Figures suggest the existence of sub-regions characterized by different precipitation regimes. In fact, Fig. 4a shows that the southwest area may correspond to a distinct sub-region due to receiving a noticeable amount of precipitation in autumn. The southernmost area may also correspond to another sub-region where the largest share of the annual precipitation occurs in winter, in addition to a noticeable percentage in summer (Fig. 4b and d). The northern part clearly shows other distinctive characteristics such as the occurrence of the largest percentage of annual precipitation during spring and 

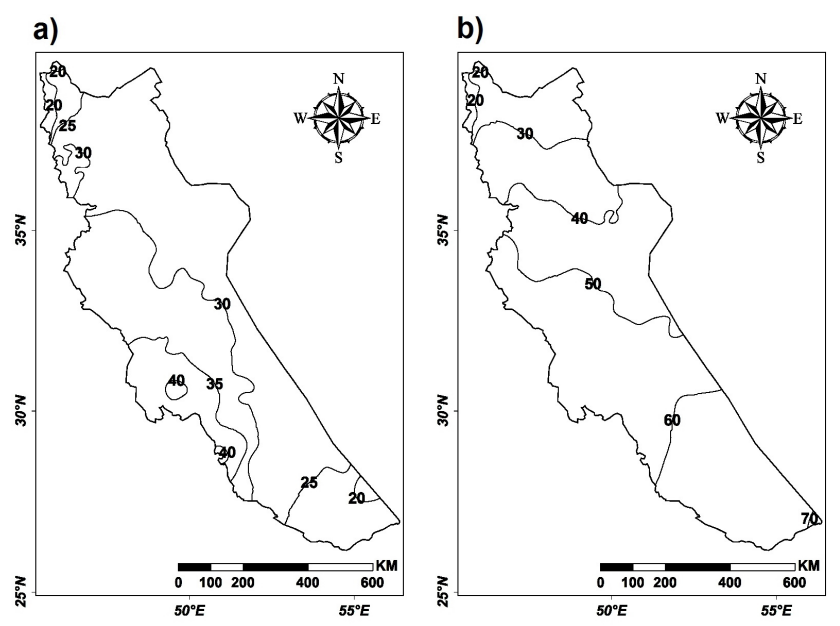

c)
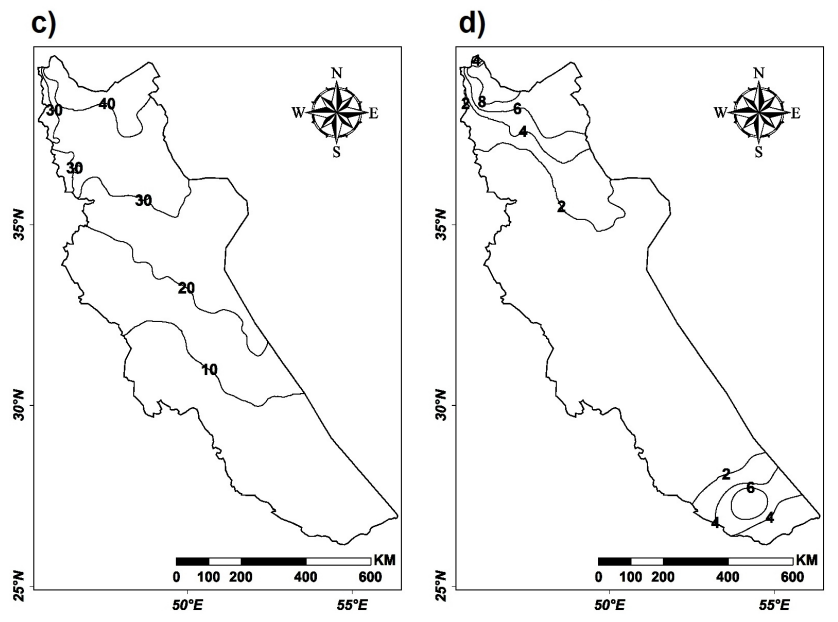

Fig. 4. Percentage of (a) autumn, (b) winter, (c) spring and (d) summer precipitation in western Iran. Unit is \%.

a considerable percentage in summer (Fig. $4 \mathrm{c}$ and d). Thus, in order to identify objectively the precipitation sub-regions, the seasonal precipitation amounts and the percentage of annual precipitation occurring in each season of the year appear to be suitable input variables for PCA and CA applications.

\subsection{Intra-annual precipitation variability}

Intra-annual precipitation variability across the study area was assessed using the PCI, mapped in Fig. 5. In the northern regions, the PCI values lower than 20 denote the seasonality of the rainfall distribution. Differently, the southern areas have $\mathrm{PCI}>25$, with a steep increasing gradient from north to south, denoting a high monthly variability in the rainfall amounts. The highest PCI values are observed in the Persian Gulf coast, in the south, with PCI ranging from 35 to 40 , indicating that most of the precipitation in this area falls in only a few months. The water stress during the hot summer season is there very intense considering the lack of rainfall

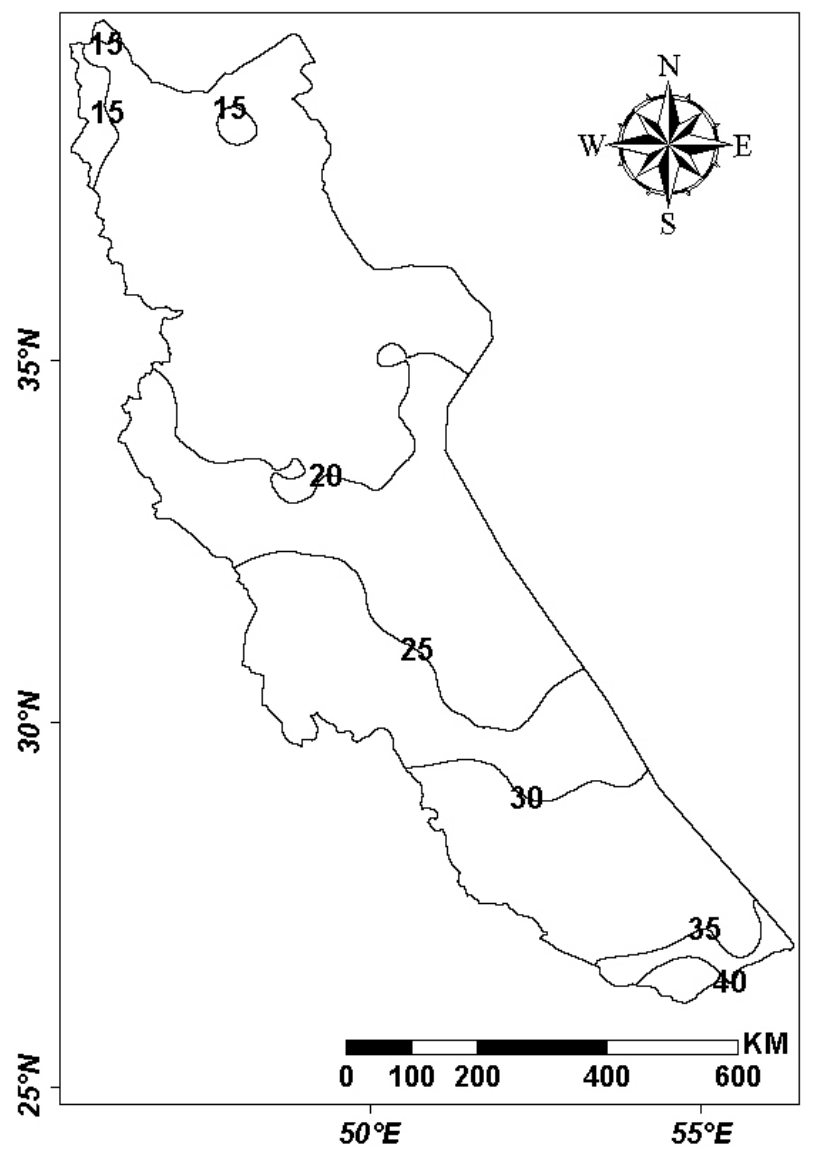

Fig. 5. Spatial distribution of PCI in western Iran.

and the high temperatures. Therefore, also the PCI appears to be a suitable input variable for PCA and CA applications in view of the precipitation regionalization.

\subsection{Precipitation-based regionalization}

We applied first the PCA to the variables computed for the whole stations. Based on Fig. 6, which shows the first nine eigenvalues of the PCA with the corresponding 95\% confidence intervals, we have selected only the first four principal components for Varimax rotation. The rotated PC loadings, the eigenvalues, and the explained and cumulative variances of the retained PCs are listed in Table 1. The four leading PCs explain $97.8 \%$ of the total variance. High loadings $(>0.7)$ indicate good correlations between the variables and the PCs.

The first PC loading, $\mathrm{PC}_{1}$, explains $40.6 \%$ of the total variance. It has high positive values on spring precipitation, both seasonal mean amount and seasonal percentage, and high negative values on PCI and percentage of winter precipitation. The first standardized PC score, shown in Fig. 7a, shows positive values in the north and negative values in the south. This means that the northern part of the western Iran 


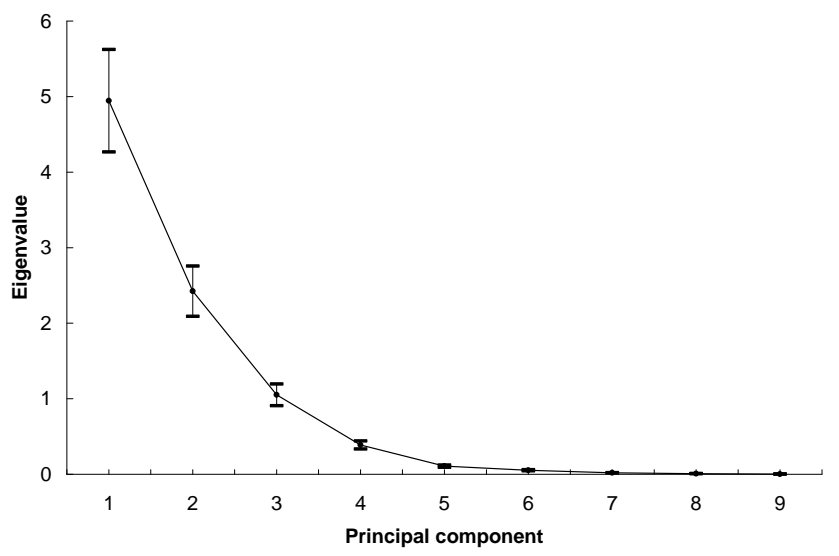

Fig. 6. First nine eigenvalues and the corresponding errorbars at 95\% confidence level resulting from the R-mode PCA applied to the nine precipitation-derived variables listed in the first column of Table 1.

is characterized by considerable amount and percentage of spring precipitation. The pronounced negative values of $\mathrm{PC}_{1}$ score in the southern part of the study area concern an area with a high percentage of winter precipitation and the highest PCI values, i.e., there is a concentration of annual precipitation in a few winter months. This implies that moving to the north the contribution of winter precipitation decreases in favour of an increase in percentage of spring precipitation and a decrease of the PCI values.

The second PC loading, $\mathrm{PC}_{2}$, with $25.0 \%$ of explained variance, has high positive values on mean autumn and winter precipitation amounts. Figure $7 \mathrm{~b}$ shows the corresponding PC score with highest values in the Zagros Mountain and a sharp decrease gradient to all directions. This spatial pattern indicates that the mountainous region of the western Iran is characterized by high amounts of autumn-winter precipitation, which is due to the orographic effects. The negative values of $\mathrm{PC}_{2}$ score in northern, eastern and southern parts of the western Iran imply that the mean winter and autumn precipitation there are lower than the spatial averages of precipitation across the study area in these seasons.

The $\mathrm{PC}_{3}$ loading, explaining $19.7 \%$ of the total variance, has high positive values on the mean amount and percentage of summer precipitation. The high positive values of $\mathrm{PC}_{3}$ score (Fig. 7c), greater than one standard deviation, in the south and north of the study area show that there, differently from the other areas in western Iran, occur a non-negligible precipitation during summer. This may be attributed to the convective mechanisms due to surface heating which, in the north, are combined with an orographic effect, and in the south add to a condensed travelling moist air moving over the warm water of the Persian Gulf.
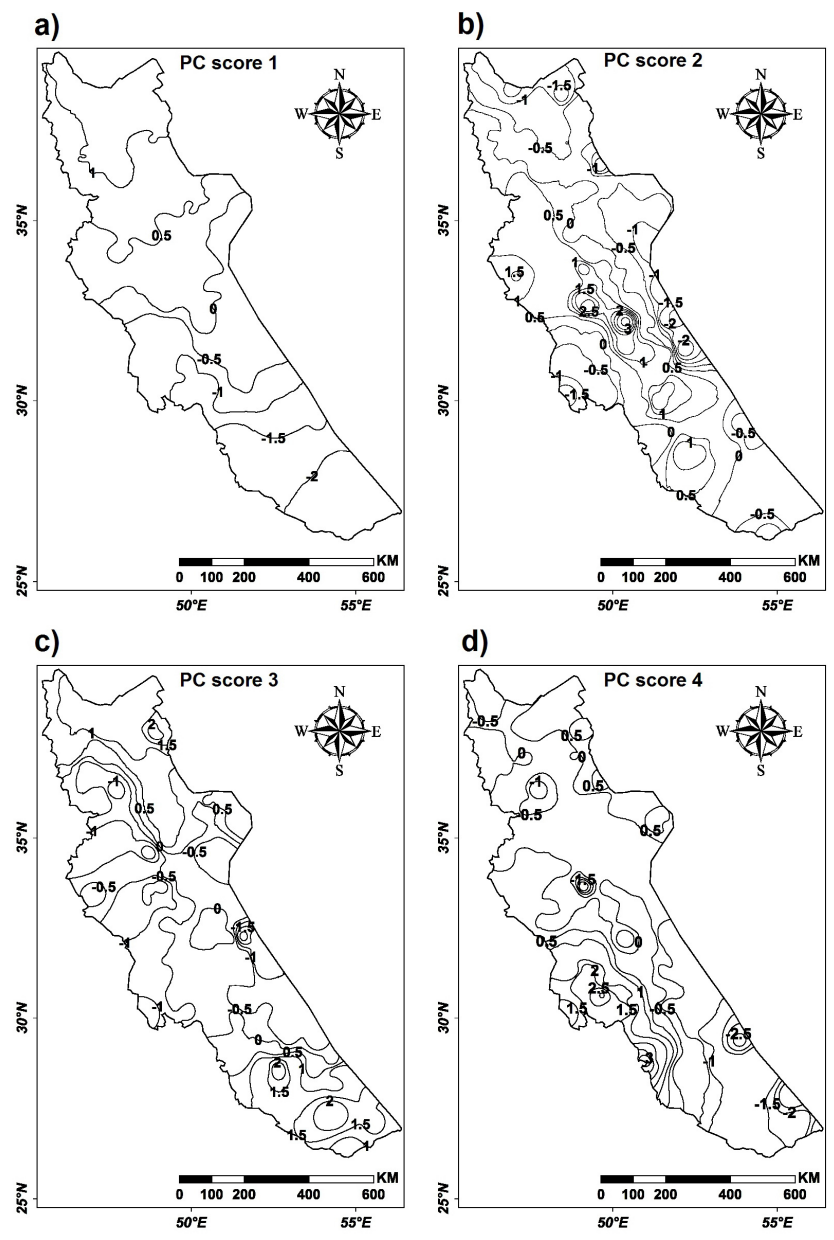

Fig. 7. Spatial distribution of the standardized Varimax rotated PC scores across western Iran. Unit is dimensionless.

The $\mathrm{PC}_{4}$ loading explains $12.5 \%$ of the total variance and has high positive value on the percentage of autumn precipitation. As shown in Fig. 7d, the corresponding spatial pattern of $\mathrm{PC}_{4}$ score indicates that the southwestern part of the region is characterized by a large percentage of autumnal precipitation, thus indicating the importance and magnitude of autumnal precipitation. This precipitation can be related to the Sudanian currents, which pass over the warm water of the Red sea and Persian Gulf.

By applying the CA to the above PC scores five distinct sub-regions have been identified (see Fig. 8).

\subsection{Characteristics of the identified sub-regions}

In order to verify that the five identified sub-regions are really characterized by different seasonal precipitation regimes, we have considered for each season the distribution of the cumulated precipitation at five stations representative of the sub-regions (Orumieh for AZ, Isfahan for EZ, Kermanshah for WZ, Ahvaz for PG and Bandarabas for PH). The Kolmogorov-Smirnov test has been applied to check the 


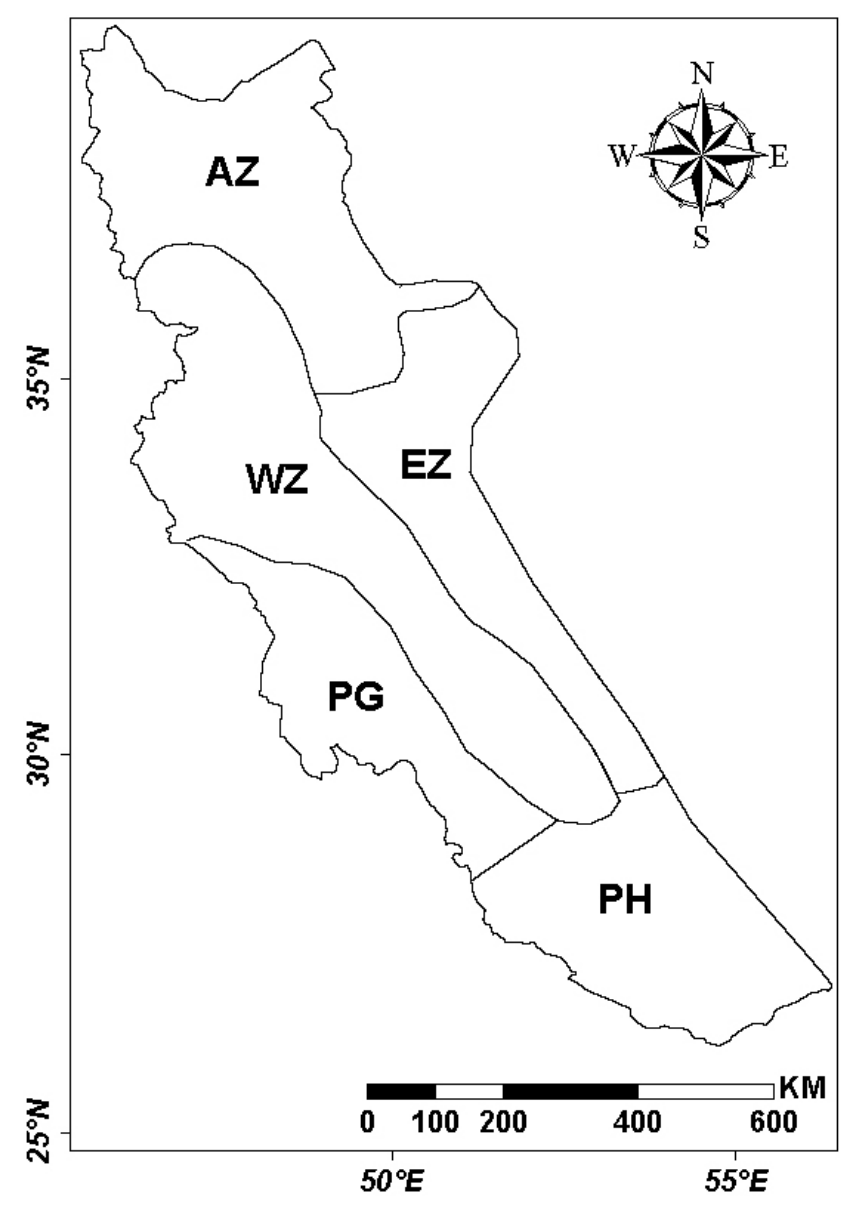

Fig. 8. Precipitation-based regionalization in western Iran.

null hypothesis that the distributions are the same (see Table 2). According to Table 2, it seems that in autumn all the sub-regions are characterized by independent precipitation regimes. Only for AZ and PG regions we cannot reject the hypothesis that the distributions are the same; since the two regions are far away, this is probably due to the shortness of the data set that represents a great limitation for the statistical test. The same occurs in winter for AZ-PG, AZ$\mathrm{PH}$, while rejecting the independency of PG and PH might be attributed to the similar distributions of winter precipitation in both sub-regions. In the case of spring, the northern part and highlands of WZ get remarkable precipitation like $\mathrm{AZ}$ and this might be the reason why we cannot reject the null hypothesis for these regions. Also the distributions of spring precipitation in EZ and PG cannot be considered different but again a longer data set should be used to better verify this result. For what concerns summer, the precipitation is mainly concentrated in AZ, while the other regions get just a few millimetres of precipitation; this might justify the fact that we cannot reject the null hypothesis for EZ-WZ, EZ-PH and WZ-PH. Thus, besides the shortness of the time
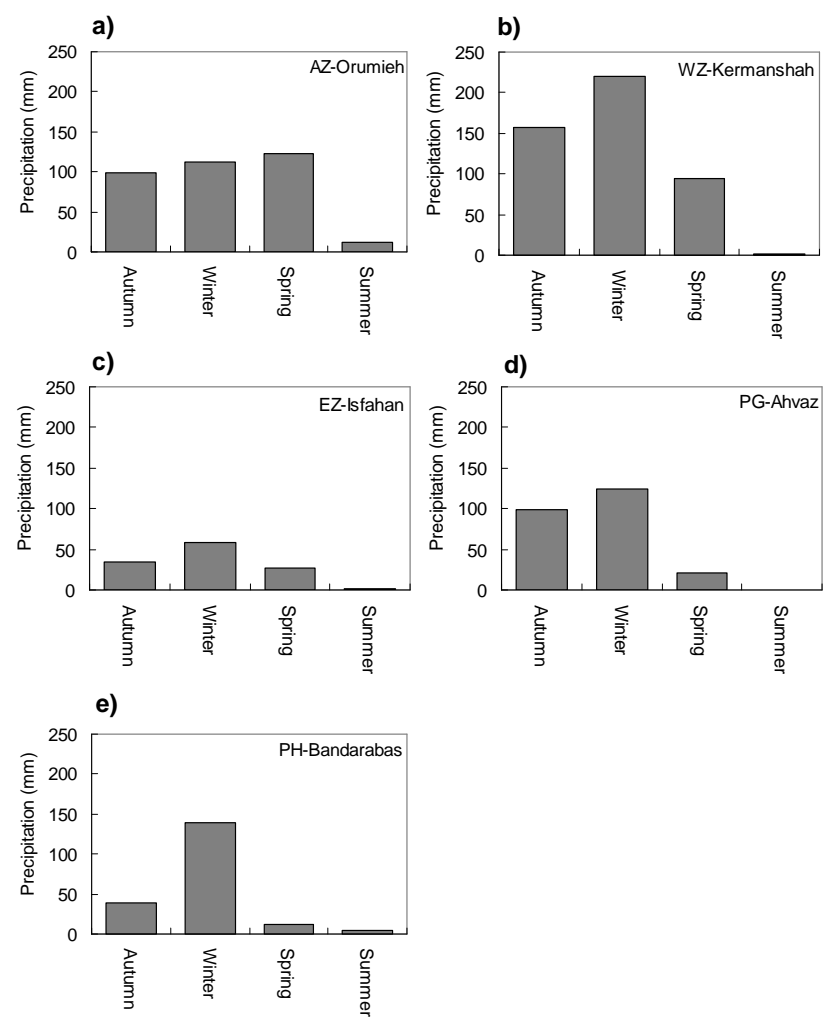

Fig. 9. Time means of the seasonal cumulated precipitation at the five stations representative of the sub-regions. Unit is $\mathrm{mm}$.

series available for the analysis, we can conclude that the regionalization here proposed provides rather independent seasonal precipitation regimes in western Iran that can be used for water resources management purposes.

The statistical characteristics of precipitation climatology for the identified sub-regions are shown in Table 3. Furthermore, to better highlight the different seasonal precipitation amounts in the five areas we have considered the time means of the seasonal cumulated precipitation at the stations representative of the sub-regions (see Fig. 9).

The main features of the five sub-regions can be summarized as follows:

i) The Azarbayjan sub-region (AZ) is located in the north of the study area. It is identified as a sub-region due to the low values of PCI and maximum precipitation in spring (Table 3, Fig. 9a). AZ experiences the highest percentage of rainfall during spring, even though about $26 \%$ and $30 \%$ of precipitation occurs in autumn and winter respectively. Moreover, the percentage of summer precipitation in AZ is the highest among all subregions. These features lead to a relatively uniform distribution of precipitation during the year, which is evidenced by low PCI values, ranging from 15 to 20 . This 
relatively uniform distribution of precipitation relates to the latitude that favours the mitigating influences of the Caspian sea in addition to the effects of westerlies during autumn and spring;

ii) The Western Zagros sub-region (WZ), which mostly concerns mountain and highlands areas, has the highest annual precipitation among all sub-regions $(590 \mathrm{~mm})$. The winter and autumn precipitation correspond to respectively 51.1 and $30.6 \%$ of total rainfall and are the main contributors to annual precipitation (Table 3). The percentage of spring precipitation is small $(18.0 \%)$ while that of summer $(0.3 \%)$ is negligible. The high annual and seasonal precipitation amounts in WZ relate to the orographic and wind side effects of the Zagros chain. The high standard deviation and wide ranges of annual and seasonal precipitation in WZ may be attributed to the high inter-station variability of precipitation amounts, which is common in mountainous areas due to the differences in elevation and exposition to the wind transporting moist air;

iii) The Eastern Zagros sub-region (EZ) has annual and seasonal precipitation lower than $\mathrm{WZ}$ due to rain shadow effects produced by the Zagros Mountains, and due to lower elevation of the sites (Fig. 9c). The annual, winter and autumnal precipitation amounts are far less than in WZ, while the percentage of spring and summer precipitation is higher. This behaviour relates to higher temperature and the occurrence of convective activities in those seasons. The PCI values in EZ and WZ subregions are similar, with an average near 21 , indicating that precipitation regimes in both sub-regions are marked by seasonality;

iv) The Persian Gulf sub-region (PG) encompasses the south and southwest foothills of Zagros Mountains. Its maximum precipitation occurs in winter $(55 \%)$ and autumn (37\%), while in spring and summer the share of precipitation is very low ( 7.5 and $0.2 \%$, respectively). The precipitation is highly concentrated in winter and autumn months (Table 3, Fig. 9d), which correspond to a high PCI value;

v) The Pars-Hormoz sub-region $(\mathrm{PH})$, is located in the south of the study area. Similarly to the PG region, it has high PCI values and low annual precipitation amount. PH differs from other sub-regions due to its very high concentration of precipitation in winter (67\%) and very high PCI, the highest among all sub-regions. The autumnal precipitation is low (Fig. 9e), which may be attributed to weakness of westerly winds and their flanks in this season, which are not enough strong to affect this southern part of the country. During the winter season the westerlies become strong and dominate the southernmost of the study area, bringing substantial precipitation especially when the westerly systems
Table 2. The resultant Kolmogorov-Smirnov test applied to the distributions of the seasonal precipitation at the five representative stations. With $H=1$ you can and $H=0$ you cannot reject the hypothesis that the distributions are the same. $P$ denotes $\mathrm{P}$-values.

\begin{tabular}{|c|c|c|c|c|c|}
\hline & & $\begin{array}{l}\text { Isfahan } \\
\text { EZ }\end{array}$ & $\begin{array}{l}\text { Kermanshah } \\
\text { WZ }\end{array}$ & $\begin{array}{l}\text { Ahvaz } \\
\text { PG }\end{array}$ & $\begin{array}{l}\text { Bandarabas } \\
\mathrm{PH}\end{array}$ \\
\hline Autumn & $\begin{array}{l}\text { Orumieh } \\
\text { AZ } \\
\text { Isfahan } \\
\text { EZ } \\
\text { Kermanshah } \\
\text { WZ } \\
\text { Ahvaz } \\
\text { PG }\end{array}$ & $\begin{array}{l}H=1 \\
P<0.01\end{array}$ & $\begin{array}{l}H=1 \\
P<0.01 \\
H=1 \\
P<0.01\end{array}$ & $\begin{array}{l}H=0 \\
P=0.84 \\
H=1 \\
P<0.01 \\
H=1 \\
P=0.01\end{array}$ & $\begin{array}{l}H=1 \\
P<0.01 \\
H=1 \\
P=0.02 \\
H=1 \\
P<0.01 \\
H=1 \\
P<0.01\end{array}$ \\
\hline Winter & $\begin{array}{l}\text { Orumieh } \\
\text { AZ } \\
\text { Isfahan } \\
\text { EZ } \\
\text { Kermanshah } \\
\text { WZ } \\
\text { Ahvaz } \\
\text { PG }\end{array}$ & $\begin{array}{l}H=1 \\
P<0.01\end{array}$ & $\begin{array}{l}H=1 \\
P<0.01 \\
H=1 \\
P<0.01\end{array}$ & $\begin{array}{l}H=0 \\
P=0.64 \\
H=1 \\
P<0.01 \\
H=1 \\
P<0.01\end{array}$ & $\begin{array}{l}H=0 \\
P=0.17 \\
H=1 \\
P<0.01 \\
H=0 \\
P<0.01 \\
H=1 \\
P=0.28\end{array}$ \\
\hline Spring & $\begin{array}{l}\text { Orumieh } \\
\text { AZ } \\
\text { Isfahan } \\
\text { EZ } \\
\text { Kermanshah } \\
\text { WZ } \\
\text { Ahvaz } \\
\text { PG }\end{array}$ & $\begin{array}{l}H=1 \\
P<0.01\end{array}$ & $\begin{array}{l}H=0 \\
P=0.09 \\
H=1 \\
P<0.01\end{array}$ & $\begin{array}{l}H=1 \\
P<0.01 \\
H=0 \\
P=0.44 \\
H=1 \\
P<0.01\end{array}$ & $\begin{array}{l}H=1 \\
P<0.01 \\
H=1 \\
P<0.01 \\
H=1 \\
P<0.01 \\
H=1 \\
P<0.01\end{array}$ \\
\hline Summer & $\begin{array}{l}\text { Orumieh } \\
\text { AZ } \\
\text { Isfahan } \\
\text { EZ } \\
\text { Kermanshah } \\
\text { WZ } \\
\text { Ahvaz } \\
\text { PG }\end{array}$ & $\begin{array}{l}H=1 \\
P<0.01\end{array}$ & $\begin{array}{l}H=1 \\
P<0.01 \\
H=0 \\
P=0.28\end{array}$ & $\begin{array}{l}H=1 \\
P<0.01 \\
H=1 \\
P<0.01 \\
H=1 \\
P<0.01\end{array}$ & $\begin{array}{l}H=1 \\
P<0.01 \\
H=0 \\
P=0.64 \\
H=0 \\
P=0.84 \\
H=1 \\
P=0.02\end{array}$ \\
\hline
\end{tabular}

combine with the Sudanian flows coming from southwest. Therefore, the PCI has the highest value in $\mathrm{PH}$ (about 35), indicating concentration of precipitation in the few months of winter season. The precipitation in summer $(2.8 \%)$ is originated by convective storms developing in low-level moist air drawn northward from the Persian Gulf (Alijani and Harman, 1985).

Thus, results suggest that the Zagros Mountain plays a main role in determining the shape and main axes of the sub-regions in western Iran. The WZ and EZ sub-regions are separated by the main axis of Zagros Mountain, stretching from northwest to southeast. On average, WZ is characterized by mountains with higher elevation than EZ and it extends orthogonally to the rain bearing systems moving from west to east; thus, it receives higher precipitation amounts than EZ owing to orographic mechanisms. The PG sub-region, which encompasses the foothills of Zagros, is also influenced by the orography. The AZ sub-region in the north and the PH sub-region in the south, instead, have west-east directions with respect to the Zagros chain, and the 
Table 3. Statistical characteristics of the precipitation in the identified sub-regions. SD stands for standard deviation. Unit for SD and mean rainfall values is $\mathrm{mm}$.

\begin{tabular}{|c|c|c|c|c|c|c|c|c|c|c|c|}
\hline Region & Statistics & $\begin{array}{l}\text { Mean } \\
\text { annual } \\
\text { rainfall } \\
(\mathrm{mm})\end{array}$ & $\begin{array}{l}\text { Mean } \\
\text { autumn } \\
\text { rainfall } \\
(\mathrm{mm})\end{array}$ & $\begin{array}{l}\text { Mean } \\
\text { winter } \\
\text { rainfall } \\
(\mathrm{mm})\end{array}$ & $\begin{array}{l}\text { Mean } \\
\text { spring } \\
\text { rainfall } \\
(\mathrm{mm})\end{array}$ & $\begin{array}{l}\text { Mean } \\
\text { summer } \\
\text { rainfall } \\
(\mathrm{mm})\end{array}$ & $\begin{array}{l}\% \\
\text { of autumn } \\
\text { rainfall }\end{array}$ & $\begin{array}{l}\% \\
\text { of winter } \\
\text { rainfall }\end{array}$ & $\begin{array}{l}\% \\
\text { of spring } \\
\text { rainfall }\end{array}$ & $\begin{array}{l}\% \\
\text { of summer } \\
\text { rainfall }\end{array}$ & PCI \\
\hline \multirow[t]{4}{*}{$\mathrm{AZ}$} & Mean & 358.1 & 100.8 & 124.9 & 116.9 & 12.7 & 28.0 & 34.1 & 34.0 & 3.9 & 17 \\
\hline & SD & 98.1 & 33.8 & 51.5 & 23.8 & 8.2 & 2.3 & 7.0 & 6.4 & 2.7 & 1.5 \\
\hline & Maximum & 646.8 & 195.0 & 236.6 & 196.4 & 43.7 & 32.1 & 48.1 & 46.7 & 9.7 & 20.5 \\
\hline & Minimum & 208.7 & 53.5 & 47.6 & 79.1 & 3.1 & 22.7 & 22.1 & 20.5 & 0.6 & 14.3 \\
\hline \multirow[t]{4}{*}{ WZ } & Mean & 588.9 & 180.9 & 306.3 & 100.1 & 1.6 & 30.6 & 51.1 & 18.0 & 0.3 & 21 \\
\hline & SD & 230.0 & 72.6 & 140.8 & 39.6 & 1.5 & 2.2 & 7.1 & 7.5 & 0.3 & 2.4 \\
\hline & Maximum & 1444.5 & 412.6 & 809.6 & 216.8 & 5.4 & 33.4 & 62.7 & 38.2 & 1.1 & 27.9 \\
\hline & Minimum & 331.5 & 85.3 & 116.5 & 36.3 & 0.0 & 25.4 & 35.1 & 7.3 & 0.0 & 17.1 \\
\hline \multirow[t]{4}{*}{ EZ } & Mean & 255.1 & 75.8 & 117.3 & 59.1 & 2.9 & 29.4 & 46.2 & 23.2 & 1.2 & 21 \\
\hline & SD & 73.4 & 24.3 & 37.5 & 22.4 & 1.3 & 1.9 & 6.6 & 5.7 & 0.5 & 2.3 \\
\hline & Maximum & 377.9 & 116.0 & 199.6 & 98.1 & 6.4 & 32.4 & 61.1 & 35.1 & 2.4 & 28.0 \\
\hline & Minimum & 111.0 & 31.1 & 56.7 & 22.2 & 0.7 & 24.7 & 33.3 & 9.7 & 0.5 & 17.6 \\
\hline \multirow[t]{4}{*}{ PG } & Mean & 299.9 & 110.3 & 166.4 & 22.6 & 0.6 & 37.0 & 55.3 & 7.5 & 0.2 & 29 \\
\hline & SD & 67.3 & 22.1 & 40.5 & 8.2 & 0.7 & 2.6 & 2.4 & 2.1 & 0.3 & 2.9 \\
\hline & Maximum & 410.4 & 143.6 & 231.2 & 40.1 & 2.8 & 42.3 & 60.0 & 11.5 & 1.0 & 37.3 \\
\hline & Minimum & 166.3 & 59.6 & 87.5 & 7.8 & 0.0 & 33.8 & 50.8 & 3.0 & 0.0 & 25.2 \\
\hline \multirow[t]{4}{*}{$\mathrm{PH}$} & Mean & 240.3 & 56.3 & 160.1 & 17.6 & 6.4 & 23.2 & 66.7 & 7.3 & 2.8 & 35 \\
\hline & SD & 60.5 & 17.7 & 40.4 & 5.1 & 4.7 & 2.7 & 2.4 & 1.6 & 2.3 & 4.8 \\
\hline & Maximum & 336.8 & 78.3 & 230.3 & 26.5 & 17.5 & 26.5 & 71.6 & 9.9 & 8.0 & 44.9 \\
\hline & Minimum & 152.1 & 33.0 & 103.4 & 8.3 & 1.9 & 17.6 & 63.3 & 5.4 & 0.8 & 28.5 \\
\hline
\end{tabular}

Table 4. Values of angular coefficients $\left(p_{1}\right)$ and the intercepts $\left(p_{2}\right)$, with the corresponding error bands at 95\% confidence level, Sum Square Error (SSE), the R-square statistics of the linear trend (i.e. $y=p_{1}\left(x_{\text {year }}-1966\right)+p_{2}$, with $x_{\text {year }}$ from 1966 to 2000), and the Man-Kendall statistics of the regional annual PI time series. The critical values for the Man-Kendall statistics test at P-value=0.1, 0.05 and 0.01 are 1.645 , 1.96 and 2.576 , respectively.

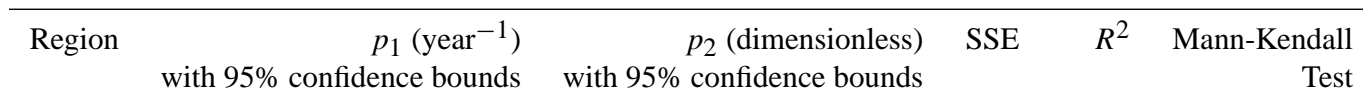

\begin{tabular}{lrrrrr}
\hline AZ & $-.025(-.059,-.009)$ & $.377(-.298,1.052)$ & 33.2 & 0.062 & -1.39 \\
WZ & $-.006(-.042, .029)$ & $.056(-.646, .758)$ & 35.8 & 0.004 & -0.18 \\
EZ & $-.009(-.044, .026)$ & $.107(-.590, .805)$ & 35.4 & 0.008 & 0.0 \\
PG & $.015(-.019, .049)$ & $-.282(-.957, .394)$ & 33.2 & 0.023 & 0.97 \\
PH & $.024(-.010, .057)$ & $-.435(-1.097, .227)$ & 31.9 & 0.060 & 1.18 \\
\hline
\end{tabular}

orographic effects are not the main source of rainfall as referred above. Thus, the present precipitation-based regionalization seems to better capture the orographic features of precipitation than former studies did (Domroes et al., 1998; Dinpashoh et al. 2004). The results are in agreement with the studies by Domroes et al. (1998) and Dinpashoh et al. (2004) in representing the $\mathrm{AZ}$ sub-region. However, the remaining identified sub-regions (WZ, EZ, PG and PH) in this work do not coincide with the results of the earlier studies. Such differences may be related to the denser and better-distributed network of rainfall stations used for the analysis. 

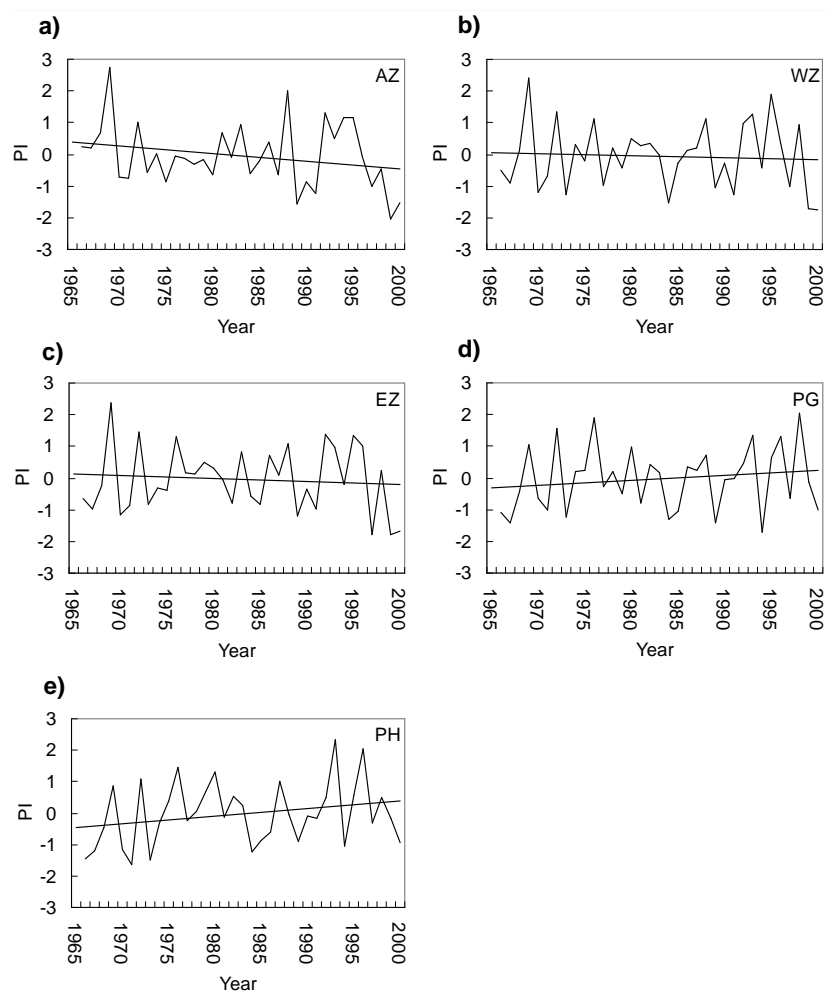

Fig. 10. Time variability of the annual PI time series for the five identified sub-regions. Straight lines denote the fitting linear trend.

4.5 Time variability of the standardized annual precipitation anomaly

The time variability of annual $\mathrm{PI}_{t}$ time series for the five identified sub-regions is presented in Fig. 10. Results for the AZ sub-region (Fig. 10a) show that wet periods occurred during the hydrological years 1968/69, 1971/72, 1987/88, 1991/92 and 1993/95, while the area experienced the major droughts $\left(\mathrm{PI}_{t}<-1\right)$ in $1988 / 91$ and 1997/2000. A weak long-term trend towards negative values, i.e. dry periods, is also detectable that explains just $6.2 \%$ of the variance of the signal (Table 4).

The $\mathrm{PI}_{t}$ time series for WZ and EZ (Fig. 10b and c) have fluctuations around the long-term average without showing any significant long-term linear trend. It must be noted that the precipitation index time series for these two sub-regions have high positive correlation with that for $\mathrm{AZ}$, i.e. 0.75 and 0.78 respectively with $\mathrm{P}$-values less than 0.05 . On the other hand, the annual $\mathrm{PI}_{t}$ for $\mathrm{WZ}$ and $\mathrm{EZ}$ behaves likewise with a correlation coefficient 0.78 and P-value less than 0.05 .

Results for PG and PH sub-regions (Fig. 10d and e) show similar time behaviours with correlation coefficient 0.84 . On the other hand, the precipitation index time series in these southern regions have positive correlation (between 0.65 and
0.75) also with $\mathrm{PI}_{t}$ from WZ and EZ. In both PG and PH regions particularly wet periods characterized the hydrological years 1971/72, 1975/76, 1992/93 and 1995/96, while severe droughts occurred during the years 1965/67, 1970/71, 1972/73, 1983/84, 1993/94 and 1999/2000. Long-term linear trends towards positive values are also detectable in both subregions though they explain small percentages of the variance of the signals and are not statistically significant (Table 4).

These results are in agreement with those by Raziei et al. (2008), who analyzed the space-time variability of hydrological drought in western Iran using the SPI on 12-month time scale. In that paper the authors identified two regions characterized by different drought variability, i.e. the north and south of western Iran. Also a long-term linear trend towards dry periods has been found to characterize the SPI in northern part of the region, while a weak positive trend has been unveiled in the southern. The analysis of drought here carried out by applying the precipitation index supports that by Raziei et al. (2008), since, due to the correlations among the $\mathrm{PI}_{t}$ time series, the sub-regions with different climatic variability reduce to two, i.e. the $\mathrm{AZ}$ and $\mathrm{PG}-\mathrm{PH}$, while $\mathrm{WZ}$ and EZ seem to be as transition regions between the northern and southern sectors. This means that for water resources management purposes the precipitation-based regionalization should be taken into account, i.e. the five identified sub-regions, while in dealing with hydrological drought two sub-regions should be considered, i.e. the northern and southern areas of western Iran.

Finally, it is worth to notice that the PI has several shortcomings, among them the hypothesis that the basic variable at single station is Gaussian distributed (for details see Kats and Glantz, 1986). On the contrary, the SPI has several properties that make the index a powerful tool for drought monitoring and related analyses (see Bordi and Sutera, 2002, and references therein). Thus, for a quantitative and objective analysis of drought variability and related climate regionalization purposes, the use of the SPI is strongly recommended as also tested for Iran (Raziei et al., 2008). The main difference, in fact, between SPI and PI is the mapping of the empirical probability distribution of cumulated precipitation into a normal distribution. This equal-probability transformation guarantees an objective comparison of the climatic conditions of different sites/areas characterized by different hydrological regimes and allows monitoring both dry and wet periods. Thus, the aim of the present PI application is just to show that using the seasonal precipitation amount five sub-regions in western Iran can be identified that are characterized by different time variability, while considering a measure of hydrological drought as the basic variable for the analysis the sub-regions with independent variability reduce to two. This is a consequence of the different concept of "precipitation regime" and "drought regime". 


\section{Conclusions}

Applying the PCA to nine precipitation-derived variables and then the CA to the four Varimax rotated PC scores, five spatially homogeneous sub-regions have been identified characterized by different precipitation regimes.

Results suggest that the spatial pattern of seasonal precipitation is highly controlled by the wide latitudinal extent of the region and by the pronounced orographic relieves. Moreover, the time of occurrence of the maximum precipitation varies from spring in the north to winter in the south.

The time behaviours of annual PI time series in the identified sub-regions show a different climatic variability in the south and the north of the study area. A long-term decreasing trend towards dry periods is detectable in the northern region (AZ), while an increasing weak long-term trend has been observed in the southern PG and PH sub-regions though they are not statistically significant.

These results obtained using the PI are in agreement with those by Raziei et al. (2008), who identified the northern and southern part of western Iran as regions with independent drought variability. This suggests that the present climate regionalization based on precipitation regimes is useful to support the water management and land use planning in the region, while in dealing with hydrological drought only two sub-regions should be considered, i.e. the northern and southern areas.

The present analysis should be checked for longer time series in order to increase the statistical confidence of the results. Also the "spatial robustness" of the identified five sub-regions with respect to the introduction of other variables as temperature and/or runoff should be investigated. These will be topics of a future work.

Acknowledgements. Data used in this study were made available by the Water Resources Institute of Iran and Iranian Meteorological Organization. This study was partially funded through the University of Tehran, and the research contract INTERREG IIIB MEDOCC 2003-03-4.4-I-010 through the Agricultural Engineering Research Center, Technical University of Lisbon, and the Department of Physics of the University of Rome "La Sapienza".

Edited by: L. A. Swatuk

\section{References}

Alijani, B. and Harman, J. R.: Synoptic climatology of precipitation in Iran, Ann. Assoc. Amer. Geogr., 75, 404-416, 1985.

Alijani, B.: The Climate of Iran, Payame Nour Publication Series, Teheran, Iran, 221 pp., 1997 (in Persian).

Bordi, I. and Sutera, A.: An analysis of drought in Italy in the last fifty years, Il Nuovo Cimento, 25C, 185-206, 2002.
Bunkers, M. J, Miller, J. R., and DeGaetano, A. T.: Definition of climate regions in the Northern plains using and objective cluster modification technique, J. Climate, 9, 130-146, 1996.

De Luís, M., Raventós, J., González-Hidalgo, J. C., Sánchez, I. R., and Cortina, J.: Spatial analysis of rainfall trends in the region of Valencia (East Spain), Int. J. Climatol., 20, 1451-1469, 2000.

De Luís M., Francisca Garcia-Cano, M., Cortina, J., Raventós, J., Gonzáles-Hidalgo, J. C., and Sánchez, J. R.: Climate trends, disturbances and short-term vegetation dynamics in a Mediterranean shrubland, Forest Ecol. Manag., 147, 25-37, 2001.

Delitala, A. M. S, Cesari, D., Chessa, P. A., and Ward, M. N.: Precipitation over Sardinia (Italy) during the 1946-1993 rainy seasons and associated large-scale climate variations, Int. J. Climatol., 20, 519-541, 2000.

Dinpashoh, Y., Fakheri-Fard, A., Moghaddam, M, Jahanbakhsh, S., and Mirnia, M.: Selection of variables for the purpose of regionalization of Iran's precipitation climate using multivariate methods, J. Hydrol., 297, 109-123, 2004.

Domroes, M., Kaviani, M., and Schaefer, D.: An analysis of regional and intra-annual precipitation variability over Iran using multivariate statistical methods, Theor. Appl. Climatol., 61, 151159, 1998.

Ehrendorfer, M.: A regionalisation of Austria's precipitation climate using principal component analysis, J. Climatol., 7, 71-89, 1987.

Fovell, R. G. and Fovell, M. Y.: Climate zones of the conterminous United States defined using cluster analysis, J. Climate, 6, 21032135, 1993.

Helsel, D. R. and Hirsch, R. M.: Statistical Methods in Water Resources, Elsevier, Amsterdam, 529 pp., 1992.

Kalkestein, L. S., Tan, G., and Skindlov, J. A.: An evaluation of three clustering procedures for use in synoptic climatological classification, J. Climate Appl. Meteor., 26, 717-730, 1987.

Katz, R. W. and Glantz, M. H.: Anatomy of a rainfall Index, Mon. Weather Rev., 114, 764-771, 1986.

Köppen, W.: Die Klimate der Erde, Walter de Gruyter, Berlin, 369 pp., 1923.

Kraus, E. B.: Subtropical droughts and cross-equatorial energy transports, Mon. Weather Rev., 105, 1009-1018, 1977.

Lolis, C. J., Bartzokas, A., and Metaxas, D. A.: Spatial covariability of the climatic parameters in the Greek area, Int. J. Climatol., 19, 185-196, 1999.

North, G. R., Bell, T. L., and Cahalan, R. F.: Sampling errors in the estimation of empirical orthogonal functions, Mon. Weather Rev., 110, 699-706, 1982.

Matias, P. G.: Análise de Frequência de Séries Hidrológicas Anuais. Dep. Engenharia Rural, Instituto Superior de Agronomia, Lisboa, 1998.

Muñoz-Díaz, D. and Rodrigo, F. S.: Spatio-temporal patterns of seasonal rainfall in Spain (1912-2000) using cluster and principal component analysis: Comparison, Ann. Geophys., 22, 14351448, 2004.

Paulo, A. A., Pereira, L. S., and Matias, P. G.: Analysis of local and regional droughts in southern Portugal using the theory of runs and the Standardised Precipitation Index, in: Tools for Drought Mitigation in Mediterranean Region, edited by: Rossi, G., Cancelliere, A., Pereira, L. S., Oweis, T., Shatanawi, M., and Zairi, A., Kluwer, Dordrecht, 55-78, 2003.

Raziei, T., Saghafian, B., Paulo, A. A., Pereira, L. S., and 
Bordi, I.: Spatial patterns and temporal variability of drought in western Iran, Water Resour. Manag., doi:10.1007/s11269008-9282-4, available at: http://www.springerlink.com/content/ b045060634017082, 2008.

Richman, M. B.: Rotation of principal components, J. Climatol., 6, 293-335, 1986.

Soltani, S., Modarres, R., and Eslamian, S. S.: The use of time series modelling for the determination of rainfall climates of Iran, Int. J. Climatol., 27, 819-829, 2007.

Thornthwaite, C. W.: The climates of North America according to a new classification, Geogr. Rev., 21, 633-655, 1931.
Vogel, R. M. and Stedinger, J. R.: Minimum variance streamflow record augmentation procedures, Water Resour. Res., 21, 715723, 1985.

Von Storch, H. and Zwiers, F.: Statistical Analysis in Climate Research, Cambridge University Press, Cambridge, 494 pp., 1999.

White, D., Richman, M., and Yarnal, B.: Climate regionalization and rotation of principal components, Int. J. Climatol., 11, 1-25, 1991.

Wilks, D. S.: Statistical Methods in the Atmospheric Sciences: An Introduction, Academic Press, San Diego, California, USA, 467 pp., 1995. 